\title{
Cerebral Salt-Wasting Syndrome Caused by Minor Head Injury
}

\author{
Toshiki Fukuoka, ${ }^{1}$ Yuko Tsurumi, ${ }^{2}$ and Arihito Tsurumi ${ }^{2}$ \\ ${ }^{1}$ Department of Neurosurgery, Nagoya University Graduate School of Medicine, Nagoya, Japan \\ ${ }^{2}$ Department of Neurosurgery, Tsurumi Neurosurgery, Koga, Ibaraki, Japan \\ Correspondence should be addressed to Toshiki Fukuoka; rugby104@gmail.com
}

Received 23 October 2016; Accepted 4 December 2016; Published 17 January 2017

Academic Editor: Vasileios Papadopoulos

Copyright (C) 2017 Toshiki Fukuoka et al. This is an open access article distributed under the Creative Commons Attribution License, which permits unrestricted use, distribution, and reproduction in any medium, provided the original work is properly cited.

\begin{abstract}
A 34-year-old woman was admitted to hospital after sustaining a head injury in a motor vehicle accident (day 1). No signs of neurological deficit, skull fracture, brain contusion, or intracranial bleeding were evident. She was discharged without symptoms on day 4 . However, headache and nausea worsened on day 8 , at which time serum sodium level was noted to be $121 \mathrm{mEq} / \mathrm{L}$. Treatment with sodium chloride was initiated, but serum sodium decreased to $116 \mathrm{mEq} / \mathrm{L}$ on day 9 . Body weight decreased in proportion to the decrease in serum sodium. Cerebral salt-wasting syndrome was diagnosed. This case represents the first illustration of severe hyponatremia related to cerebral salt-wasting syndrome caused by a minor head injury.
\end{abstract}

\section{Introduction}

Hyponatremia resulting from cerebral salt-wasting syndrome (CSWS) can occur after severe brain injury, severe cerebrovascular disease, or surgery [1-9]. Hyponatremia can result in brain edema and secondary nausea, headache, altered consciousness, and sometimes death. Close monitoring of serum $\mathrm{Na}$ levels and immediate correction of electrolyte abnormalities are therefore necessary after severe brain damage. If left untreated without correct diagnosis, severe hyponatremia may result in seizures and worsening cerebral edema [10].

However, no previous reports have described hyponatremia of CSWS occurring after minor head injury in the absence of intracranial bleeding, skull fracture, or brain contusion. This report describes the case of a patient with minor head injury who developed severe hyponatremia due to CSWS.

\section{Case Report}

A 34-year-old woman with no significant past medical history sustained an injury to the right forehead in a motor vehicle accident (day 1). She was not taking any regular medications. Physical examination revealed no traumatic wounds other than a thin subcutaneous hematoma on the right forehead.
She presented with headache and nausea, and Glasgow coma scale score was 14 (E3, V5, M6), but no obvious focal neurological signs were present, including amnesia. Furthermore, computed tomography (CT) of the head revealed no skull fracture, intracranial hemorrhage, or brain contusion. Complete blood cell (CBC) count and serum biochemistry revealed no abnormalities, and serum $\mathrm{Na}$ concentration was normal $(141 \mathrm{mEq} / \mathrm{L})$. She was hospitalized for observation under a diagnosis of brain concussion. By day 2, Glasgow coma scale score had normalized and symptoms of headache and nausea had almost resolved. On day 3, serum $\mathrm{Na}$ was still within the normal range but had decreased to $135 \mathrm{mEq} / \mathrm{L}$. $\mathrm{CBC}$ and serum biochemistry revealed no abnormalities, and the patient was discharged without symptoms on day 4 .

After discharge from hospital, she began to feel severe and gradually worsening fatigue and nausea and finally presented to the emergency department on day 8. Head CT revealed no abnormal findings. Blood testing disclosed serum $\mathrm{Na}$ of $121 \mathrm{mEq} / \mathrm{L}$ and serum $\mathrm{Cl}$ of $90 \mathrm{mEq} / \mathrm{L}$, while serum biochemistry showed no other abnormalities. Skin turgor was slightly diminished, suggesting decreased circulating plasma volume. She was therefore hospitalized for evaluation and management of hyponatremia.

Treatment was initiated via intravenous saline and oral administration of salt with frequent monitoring of serum $\mathrm{Na}$ levels. Body weight was measured daily to help distinguish 


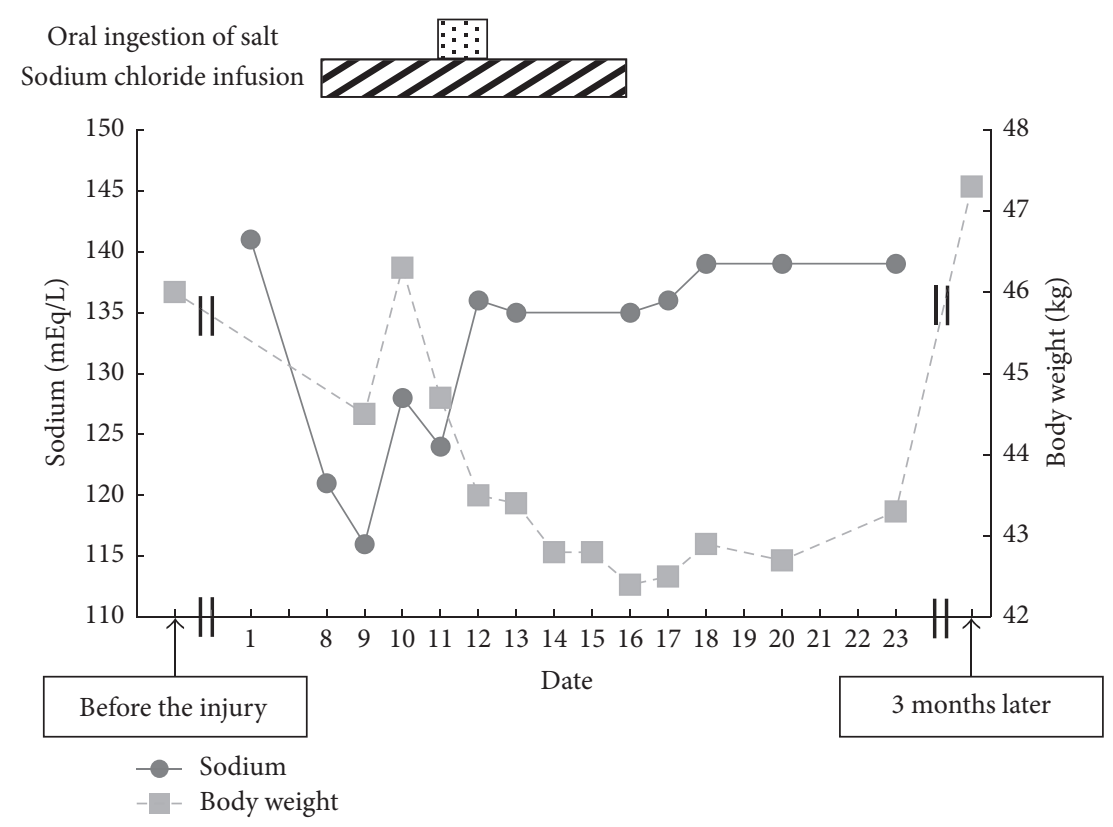

FIGURE 1: Clinical course of treatment and examinations.

between the presence of CSWS, syndrome of inappropriate secretion of antidiuretic hormone (SIADH), and other disorders. Blood testing on day 9 revealed serum $\mathrm{Na}$ of $116 \mathrm{mEq} / \mathrm{L}$ and serum osmolality of $251 \mathrm{mOsm} / \mathrm{L}$ (reference range: $275-$ $285 \mathrm{mOsm} / \mathrm{L}$ ). On day 10, blood testing showed serum $\mathrm{Na}$ of $125 \mathrm{mEq} / \mathrm{L}$ (urine $\mathrm{Na}: 65 \mathrm{mEq} / \mathrm{L}$ ), serum osmolality of $251 \mathrm{mOsm} / \mathrm{L}$ (urine osmolality: $238 \mathrm{mOsm} / \mathrm{L}$ ), a urine acid level of $1.5 \mathrm{mg} / \mathrm{dL}$ (reference range: $2.3-7.0 \mathrm{mg} / \mathrm{dL}$ ), an atrial natriuretic peptide (ANP) level of $114 \mathrm{pg} / \mathrm{mL}$ (reference range: $<43 \mathrm{pg} / \mathrm{mL}$ ), a brain natriuretic peptide (BNP) level of $142 \mathrm{pg} / \mathrm{L}$ (reference range: $0-18 \mathrm{pg} / \mathrm{L}$ ), an antidiuretic hormone $(\mathrm{ADH})$ level of $0.79 \mathrm{pg} / \mathrm{mL}$ (reference range: $0.3-$ $4.2 \mathrm{pg} / \mathrm{mL}$ ), a plasma renin activity level of $<2.0 \mathrm{pg} / \mathrm{mL}$ (reference range: $2.5-21.4 \mathrm{pg} / \mathrm{mL}$ ), a thyroid-stimulating hormone (TSH) level of $2.734 \mu \mathrm{g} / \mathrm{mL}$ (reference range: $0.350-$ $4.940 \mu \mathrm{g} / \mathrm{mL}$ ), a free triiodothyronine level of $2.24 \mathrm{pg} / \mathrm{mL}$ (reference range: $1.71-3.71 \mathrm{pg} / \mathrm{mL}$ ), a free thyroxine level of $1.02 \mathrm{ng} / \mathrm{dL}$ (reference range: $0.70-1.48 \mathrm{ng} / \mathrm{dL}$ ), a morning fasting hydrocortisone level of $14.99 \mu \mathrm{g} / \mathrm{mL}$ (reference range: $6-20 \mu \mathrm{g} / \mathrm{mL}$ ), and an adrenocorticotropic hormone level of $30.2 \mathrm{pg} / \mathrm{mL}$ (reference range: $7.4-55.7 \mathrm{pg} / \mathrm{mL}$ ). In addition, body weight decreased as serum $\mathrm{Na}$ decreased.

These results, the diminished skin turgor, and the decrease in body weight indicated a diagnosis of CSWS and the absence of renal failure, thyroid dysfunction, and adrenal insufficiency. Blood testing showed serum $\mathrm{Na}$ of $129 \mathrm{mEq} / \mathrm{L}$ on day 11 (urine Na: $60 \mathrm{mEq} / \mathrm{L}$ ) and serum $\mathrm{Na}$ of $136 \mathrm{mEq} / \mathrm{L}$ (urine Na: $55 \mathrm{mEq} / \mathrm{L}$ ) on day 12. Serum $\mathrm{Na}$ subsequently remained within the normal range. On day 16 , intravenous saline infusion was terminated. Fatigue and nausea resolved as serum $\mathrm{Na}$ concentrations increased. After day 20, body weight started to improve towards baseline. She was discharged on day 24 without any subsequent recurrence of hyponatremia. Serum BNP level on day 27 had completely normalized to $10 \mathrm{pg} / \mathrm{L}$ (reference range: $0-18 \mathrm{pg} / \mathrm{L}$ ). The course of treatment is shown in Figure 1.

\section{Discussion}

CSWS is characterized by renal loss of sodium following intracranial disorders, resulting in hyponatremia and hypovolemia [11-13]. CSWS ordinarily occurs after severe brain injury, severe cerebrovascular disease, or surgery [1-9], and no previous reports have described CSWS after minor head injury. Intriguingly, lightning injury [14] and therapeutic barbiturate coma [15] may also cause CSWS. While many studies have described aspects of CSWS, the pathogenesis of renal salt wasting derived from cerebral disease is not fully understood. The most probable process involves disruption of neural inputs to the kidney and/or central production of a circulating natriuretic factor $[6,7,11,12,16,17]$. In addition, some authors have indicated that ANP and BNP exert biologic effects that could lead to CSWS $[3,6,7,18-$ 20]. The time from traumatic brain injury to development of CSWS can vary from 2 days to 2 months [2, 3, 6, 18, 21, 22]. Regarding the severity of CSWS, highly invasive surgery and the severity of findings on head CT are associated with the severity of CSWS $[9,21]$. In other words, CSWS is unlikely to occur in the absence of severe brain damage.

Differentiating between CSWS and SIADH is critical for appropriate treatment of hyponatremia, because therapeutic strategies for the two syndromes differ markedly. When hyponatremia is treated inappropriately, the patient is at increased risk of delayed ischemic deficits and/or osmotic demyelination leading to disability and mortality [23]. The primary distinction between CSWS and SIADH is whether the circulating blood volume is decreased or increased [6, 12, 24, 25]. Since some CSWS cases do not present with characteristic physical findings, comprehensive judgment is frequently needed to reach a definitive diagnosis. In the present case, serum $\mathrm{Na}$ concentrations, osmolality, ANP, BNP, ADH, diminished skin turgor, decreasing body weight, and prolonged natriuresis despite hyponatremia were 
consistent with the diagnosis of CSWS rather than SIADH. As a matter of fact, serum $\mathrm{Na}$ levels and symptoms were greatly improved with substantial hydration and $\mathrm{NaCl}$ administration.

CSWS is generally caused by severe brain injury or severe cerebrovascular disease, and head CT and magnetic resonance imaging typically reveal abnormal findings. In the present case, head CT was notable for the absence of intracranial bleeding and brain contusion. This case shows that even minor head injuries can cause disruptions to the neural inputs to the kidney and/or central production of circulating natriuretic factors that eventually contribute to CSWS. Clinicians should be aware that even minor head injury may result in CSWS, hyponatremia, and secondary symptoms.

\section{Competing Interests}

The authors declare that they have no competing interests.

\section{References}

[1] K. N. Costa, H. M. Nakamura, L. R. Da Cruz et al., "Hyponatremia and brain injury: absence of alterations of serum brain natriuretic peptide and vasopressin," Arquivos de NeuroPsiquiatria, vol. 67, no. 4, pp. 1037-1044, 2009.

[2] N. Moro, Y. Katayama, T. Igarashi, T. Mori, T. Kawamata, and J. Kojima, "Hyponatremia in patients with traumatic brain injury: incidence, mechanism, and response to sodium supplementation or retention therapy with hydrocortisone," Surgical Neurology, vol. 68, no. 4, pp. 387-393, 2007.

[3] P. C. M. Donati-Genet, J.-M. Dubuis, E. Girardin, and P. C. Rimensberger, "Acute symptomatic hyponatremia and cerebral salt wasting after head injury: an important clinical entity," Journal of Pediatric Surgery, vol. 36, no. 7, pp. 1094-1097, 2001.

[4] R. Jiménez, J. Casado-Flores, M. Nieto, and M. A. García-Teresa, "Cerebral salt wasting syndrome in children with acute central nervous system injury," Pediatric Neurology, vol. 35, no. 4, pp. 261-263, 2006.

[5] L. A. Casulari, K. N. Costa, R. C. R. Albuquerque, L. A. Naves, K. Suzuki, and L. Domingues, "Differential diagnosis and treatment of hyponatremia following pituitary surgery," Journal of Neurosurgical Sciences, vol. 48, no. 1, pp. 11-18, 2004.

[6] J. Leonard, R. E. Garrett, K. Salottolo et al., "Cerebral salt wasting after traumatic brain injury: a review of the literature," Scandinavian Journal of Trauma, Resuscitation and Emergency Medicine, vol. 23, no. 1, article no. 98, 2015.

[7] T. M. Berger, W. Kistler, E. Berendes, C. Raufhake, and M. Walter, "Hyponatremia in a pediatric stroke patient: syndrome of inappropriate antidiuretic hormone secretion or cerebral salt wasting?" Critical Care Medicine, vol. 30, no. 4, pp. 792-795, 2002.

[8] C. C. A. John and M. W. Day, "Central neurogenic diabetes insipidus, syndrome of inappropriate secretion of antidiuretic hormone, and cerebral salt-wasting syndrome in traumatic brain injury," Critical Care Nurse, vol. 32, no. 2, pp. el-e7, 2012.

[9] M. Sherlock, E. O’Sullivan, A. Agha et al., "Incidence and pathophysiology of severe hyponatraemia in neurosurgical patients," Postgraduate Medical Journal, vol. 85, no. 1002, pp. 171175, 2009.
[10] A. H. Yee, J. D. Burns, and E. F. M. Wijdicks, "Cerebral salt wasting: pathophysiology, diagnosis, and treatment," Neurosurgery Clinics of North America, vol. 21, no. 2, pp. 339-352, 2010.

[11] J. Momi, C. M. Tang, A. C. Abcar, D. A. Kujubu, and J. J. Sim, "Hyponatremia-what is cerebral salt wasting?" The Permanente Journal, vol. 14, pp. 62-65, 2010.

[12] B. F. Palmer, "Hyponatremia in patients with central nervous system disease: SIADH versus CSW," Trends in Endocrinology \& Metabolism, vol. 14, no. 4, pp. 182-187, 2003.

[13] M. Cerdà-Esteve, E. Cuadrado-Godia, J. J. Chillaron et al., "Cerebral salt wasting syndrome: review," European Journal of Internal Medicine, vol. 19, no. 4, pp. 249-254, 2008.

[14] M. Emet, I. Caner, M. Cakir, S. Aslan, and Z. Cakir, "Lightning injury may cause abrupt cerebral salt wasting syndrome," The American Journal of Emergency Medicine, vol. 28, no. 5, pp. 640.el-640.e3, 2010.

[15] M. Kontogiorgi, P. Opsimoulis, E. Diamanti-Kandarakis, and A. Karabinis, "Cerebral salt wasting syndrome in traumatic brain injury following therapeutic barbiturate coma," Acta Neurochirurgica, vol. 153, no. 8, pp. 1719-1720, 2011.

[16] S. Singh, D. Bohn, A. P. C. P. Carlotti, M. Cusimano, J. T. Rutka, and M. L. Halperin, "Cerebral salt wasting: truths, fallacies, theories, and challenges," Critical Care Medicine, vol. 30, no. 11, pp. 2575-2579, 2002.

[17] J. P. Granger, B. T. Alexander, and M. Llinas, "Mechanisms of pressure natriuresis," Current Hypertension Reports, vol. 4, no. 2, pp. 152-159, 2002.

[18] D. C. Lu, D. K. Binder, B. Chien, A. Maisel, and G. T. Manley, "Cerebral salt wasting and elevated brain natriuretic peptide levels after traumatic brain injury: 2 case reports," Surgical Neurology, vol. 69, no. 3, pp. 226-229, 2008.

[19] G. E. Sviri, J. F. Soustiel, and M. Zaaroor, "Alteration in brain natriuretic peptide (BNP) plasma concentration following severe traumatic brain injury," Acta Neurochirurgica, vol. 148, no. 5, pp. 529-533, 2006.

[20] X. Wu, H. Sha, Y. Sun et al., "N-terminal pro-B-type natriuretic peptide in patients with isolated traumatic brain injury: a prospective cohort study," Journal of Trauma, vol. 71, no. 4, pp. 820-825, 2011.

[21] S. Lohani and U. P. Devkota, "Hyponatremia in patients with traumatic brain injury: etiology, incidence, and severity correlation," World Neurosurgery, vol. 76, no. 3-4, pp. 355-360, 2011.

[22] R. Steelman, B. Corbitt, and M. F. D. Pate, "Early onset of cerebral salt wasting in a patient with head and facial injuries," Journal of Oral and Maxillofacial Surgery, vol. 64, no. 4, pp. 746747, 2006.

[23] E. F. M. Wijdicks, M. Vermeulen, A. Hijdra, and J. Van Gijn, "Hyponatremia and cerebral infarction in patients with ruptured intracranial aneurysms: is fluid restriction harmful?" Annals of Neurology, vol. 17, no. 2, pp. 137-140, 1985.

[24] J. K. Maesaka, S. Gupta, and S. Fishbane, "Cerebral salt-wasting syndrome: does it exist?” Nephron, vol. 82, no. 2, pp. 100-109, 1999.

[25] R. H. Sterns and S. M. Silver, "Cerebral salt wasting versus SIADH: what difference?" Journal of the American Society of Nephrology, vol. 19, no. 2, pp. 194-196, 2008. 


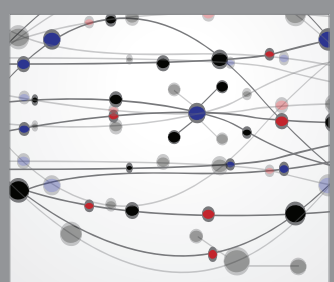

The Scientific World Journal
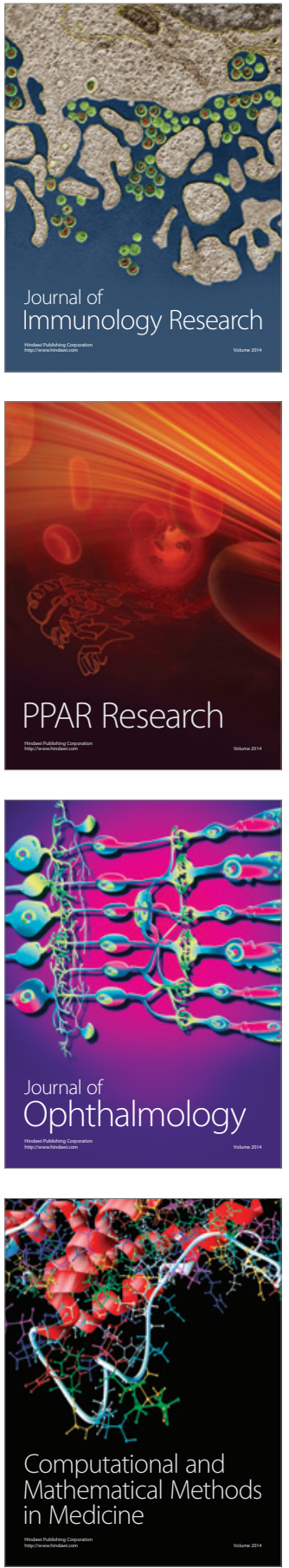

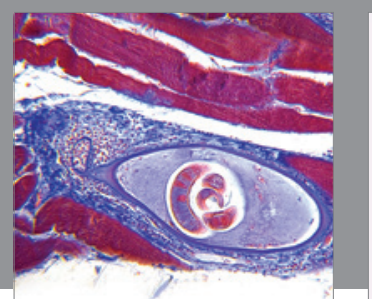

Gastroenterology Research and Practice
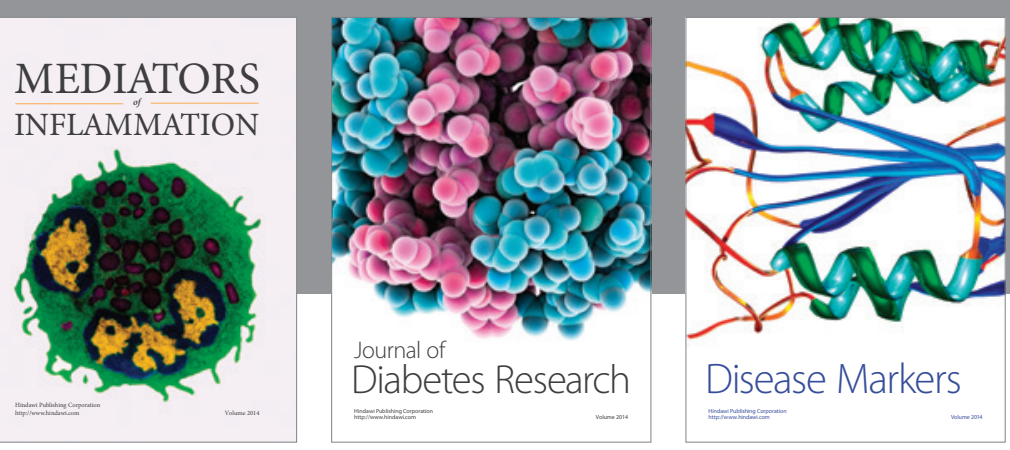

Disease Markers

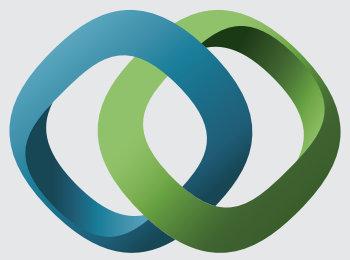

\section{Hindawi}

Submit your manuscripts at

https://www.hindawi.com
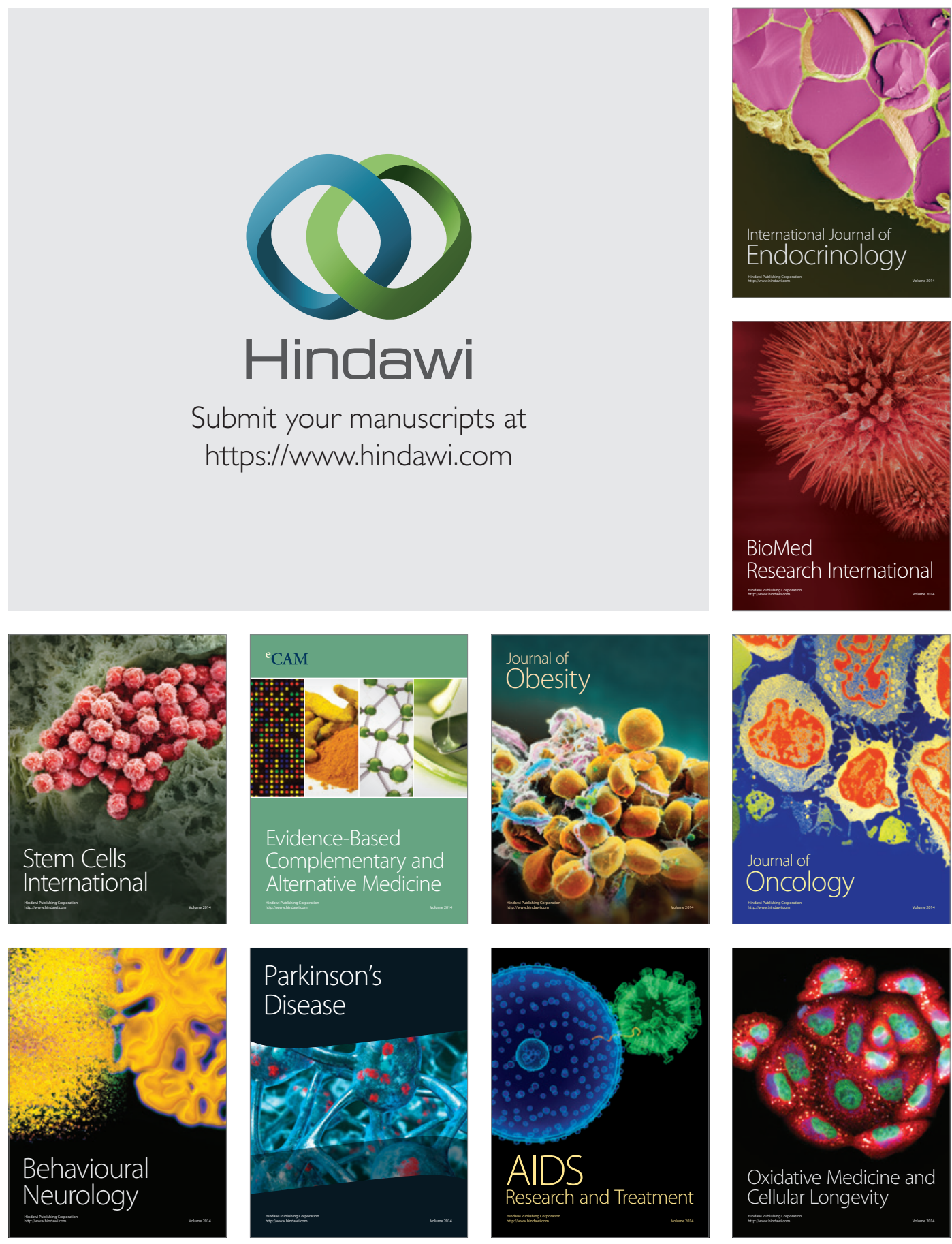